\title{
Transcription Factor Expression and Notch-Dependent Regulation of Neural Progenitors in the Adult Rat Spinal Cord
}

\author{
Shin-ichi Yamamoto, ${ }^{1,2}$ Motoshi Nagao, ${ }^{1}$ Michiya Sugimori, ${ }^{1}$ Hidetaka Kosako, ${ }^{1}$ Hirofumi Nakatomi, ${ }^{1,3}$ \\ Naoya Yamamoto, ${ }^{1,2}$ Hirohide Takebayashi, ${ }^{4}$ Yo-ichi Nabeshima, ${ }^{4,7}$ Toshio Kitamura, ${ }^{5}$ Gerry Weinmaster, ${ }^{6}$ \\ Kozo Nakamura, ${ }^{2}$ and Masato Nakafuku ${ }^{1,7}$ \\ Departments of ${ }^{1}$ Neurobioloy, ${ }^{2}$ Orthopaedic Surgery, and ${ }^{3}$ Neurosurgery, The University of Tokyo Graduate School of \\ Medicine, Tokyo 113-0033, Japan, ${ }^{4}$ Department of Pathology and Tumor Biology, University of Kyoto Graduate School \\ of Medicine, Kyoto 606-8501, Japan, 5Department of Hematopoietic Factors, Institute of Medical Science, The University \\ of Tokyo, Tokyo 108-8639, Japan, 'Department of Biological Chemistry, University of California at Los Angeles School of \\ Medicine, Los Angeles, California 90095-1737, and ${ }^{7}$ Core Research for Evolutional Science and Technology, Japan \\ Science and Technology Cooperation, Tokyo 105-0011, Japan
}

Recent studies have demonstrated that neural stem cells and other progenitors are present in the adult CNS. Details of their properties, however, remain poorly understood. Here we examined the properties and control mechanisms of neural progenitors in the adult rat spinal cord at the molecular level. Adult and embryonic progenitors commonly expressed various homeodomain-type (Pax6, Pax7, Nkx2.2, and Prox1) and basic helix-loop-helix (bHLH)-type (Ngn2, Mash1, NeuroD1, and Olig2) transcriptional regulatory factors in vitro. Unlike their embryonic counterparts, however, adult progenitors could not generate specific neurons that expressed markers appropriate for spinal motoneurons or interneurons, including Islet1, Lim1, Lim3, and HB9. Cells expressing the homeodomain factors Pax6, Pax7, and Nkx2.2 also emerged in vivo in response to injury and were distributed in unique patterns in the lesioned spinal cord. However, neither the expression of the neurogenic
bHLH factors including Ngn2, Mash1, and NeuroD1 nor subsequent generation of new neurons could be detected in injured tissue. Our results suggest that signaling through the cellsurface receptor Notch is involved in this restriction. The expression of Notch1 in vivo was enhanced in response to injury. Furthermore, activation of Notch signaling in vitro inhibited differentiation of adult progenitors, whereas attenuation of Notch signals and forced expression of Ngn2 significantly enhanced neurogenesis. These results suggest that both the intrinsic properties of adult progenitors and local environmental signals, including Notch signaling, account for the limited regenerative potential of the adult spinal cord.

Key words: neural progenitor; stem cell; spinal cord; adult neurogenesis; Notch signaling; transcription factor; injury; regeneration
Multipotential neural stem cells serve as the origin of diverse cell types during development of the CNS (McKay, 1997; Rao, 1999). During embryogenesis, neural stem cells progressively generate various types of progenitors, which are, in turn, fated to differentiate into neurons and glia in a spatially and temporally regulated manner.

In contrast to these cellular dynamics during development, it has long been believed that most of the progenitors for neurons and glia disappear after the perinatal stage, and hence the adult CNS is incapable of significant self-repair or regeneration. Many lines of recent studies have revealed, however, that neural progenitors remain in the adult CNS (Temple and Alvarez-Buylla, 1999; Gage, 2000). In particular, neural stem cells, which have

\footnotetext{
Received May 24, 2001; revised Sept. 17, 2001; accepted Oct. 3, 2001.

This work was supported by grants-in-aids from the Ministry of Health, Labor, and Welfare on Brain Science, the Ministry of Education, Science, and Culture for the Research for the Future Program, and the Tanabe Medical Frontier Foundation. We are gratef ul to Drs. Y. Ihara and M. Inagaki for providing us with antibodies. We also acknowledge the Developmental Studies Hybridoma Bank maintained by the University of Iowa for the supply of monoclonal antibodies. We thank Drs. T. Miura, A. Seichi, and S. Tanaka for technical advice for spinal surgery. We also thank Dr. K. Shimamura for valuable comments and discussion and Drs. Y. Kaziro, Y. Ihara, S. Kohsaka, and S. Yoshida for encouragement and support.

Correspondence should be addressed to Dr. Masato Nakafuku, Department of Neurobiology, The University of Tokyo Graduate School of Medicine, 7-3-1 Hongo, Bunkyo-ku, Tokyo 113-0033, Japan. E-mail: nakafuku@m.u-tokyo.ac.jp. Copyright (C) 2001 Society for Neuroscience $0270-6474 / 01 / 219814-10 \$ 15.00 / 0$
}

been defined by their ability of long-term self-renewal and multipotentiality, have been identified in the periventricular areas all along the rostrocaudal axis (Weiss et al., 1996). Neural stem cells and other types of progenitors are also present in some nonperiventricular regions (Palmer et al., 1995, 1999; Marmur et al., 1998; Kondo and Raff, 2000). Adult spinal cord also contains progenitors for neurons and glia (Weiss et al., 1996; Kehl et al., 1997; Shihabuddin et al., 1997, 2000; Johansson et al., 1999; Horner et al., 2000). However, the precise locations and details of the heterogeneity of adult progenitors in each region still remain poorly understood (Morshead and van der Kooy, 2001).

Furthermore, despite that neural progenitors remain in multiple regions, continuous neurogenesis has been detected in only a few, restricted areas in the adult CNS (Temple and AlvarezBuylla, 1999; Gage, 2000). If endogenous progenitors could be recruited to generate functional neurons in many other areas, they might represent a dormant capacity for repairing the damaged CNS (Svendsen and Smith, 1999; Horner and Gage, 2000). To pursue such a possibility, it is essential to understand in detail the properties and behavior of adult neural progenitors. It is also important to elucidate the mechanisms that control the differentiation of neural progenitors in the adult CNS.

As a first step to address these issues, here we examined the molecular properties and control mechanisms of neural progeni- 
tors in the adult rat spinal cord both in vitro and in vivo. We show that adult and embryonic progenitors commonly expressed various homeodomain-type and basic helix-loop-helix (bHLH)-type transcription factors in vitro. Cells expressing specific homeodomain factors also emerged and transiently proliferated in vivo in response to injury. However, neither production of new neurons nor the expression of neurogenic bHLH factors could be detected in injured tissue. Our results suggest that signaling through the cell-surface receptor Notch may be involved in this restriction. We show that attenuation and/or bypass of Notch signaling by a dominant-negative form of the Notch ligand Delta-like-1 (Dll1) and the neurogenic bHLH factor Ngn2 could stimulate the generation of neurons from adult progenitors. Thus, this study provides an important clue to enable recruitment of the latent regenerative potential of endogenous neural progenitors to repair the damaged spinal cord.

\section{MATERIALS AND METHODS}

Primary cultures. Young adult male Sprague Dawley rats (6-7 weeks of age and weighing $180-220 \mathrm{gm}$ ) were used in all experiments. Adult rats were killed with diethyl ether, and the dorsal part of the spinal cord was exposed by laminectomy. The segments between the fourth thoracic (T4) and sacral levels were removed as a columnar tissue block, and the medial and lateral parts of the parenchyma were separated using a microscalpel. The position of the dorsal horn, visible under the microscope, was used as a landmark (Fig. 1A). The resultant tissues were cut into small pieces and dissociated by incubation with $0.1 \%$ (w/v) trypsin (Sigma, St. Louis, MO), $0.67 \mathrm{mg} / \mathrm{ml}$ hyaluronidase (Sigma), and $0.1 \mathrm{mg} / \mathrm{ml}$ DNase I (Roche, Basel, Switzerland), with aeration with $95 \% \mathrm{O}_{2}-5 \% \mathrm{CO}_{2}$, at $37^{\circ} \mathrm{C}$ for 30 min as described previously (Weiss et al., 1996). Subsequently, trypsin was neutralized with $0.7 \mathrm{mg} / \mathrm{ml}$ ovamucoid (Sigma), and the resultant tissue suspension was triturated mechanically to yield a single cell suspension. The cells were filtered through a sterile nylon mesh $(40 \mu \mathrm{m}$; Becton Dickinson, Franklin Lakes, NJ) and placed on top of $2 \mathrm{ml}$ of fetal bovine serum (Sanko-junyaku, Tokyo, Japan) in a test tube. The sample was centrifuged at $80 \times g$ at room temperature for $5 \mathrm{~min}$, and viable cells were recovered as a pellet below the serum cushion. Numbers of viable cells were determined by staining with Trypan blue (Sigma). The spinal cord was also isolated from embryonic day 13.5 (E13.5) rat embryos. Dissociated cell suspensions were prepared as described above, except that the fractionation with a serum cushion was omitted.

Primary culture was performed according to Weiss et al. (1996), with some modifications. Floating culture was performed by using dishes coated with poly [2-hydroxy-ethyl methacrylate] $\left(1.6 \mathrm{mg} / \mathrm{cm}^{2}\right.$; Sigma) to prevent cell attachment (Torii et al., 1999). The cells were seeded at a density of $3-5 \times 10^{5}$ viable cells $/ \mathrm{ml}$ in a growth medium [1:1 mixture of a DMEM and F-12 medium (Life Technologies, Rockville, MD) supplemented with the B-27 culture supplement (Life Technologies), 20 $\mathrm{ng} / \mathrm{ml}$ bovine fibroblast growth factor 2 (FGF2) (Roche), $20 \mathrm{ng} / \mathrm{ml}$ mouse epidermal growth factor (EGF) (Roche), $2 \mu \mathrm{g} / \mathrm{ml}$ heparin (molecular mass of 3000; Sigma), $1 \mathrm{mg} / \mathrm{ml}$ bovine serum albumin (Sigma), $100 \mathrm{U} / \mathrm{ml}$ penicillin (Banyu Pharmaceutical Co. Ltd., Tokyo, Japan), and 100 $\mu \mathrm{g} / \mathrm{ml}$ streptomycin (Meiji Seika, Tokyo, Japan)]. The medium was replaced with fresh medium twice per week. At day 14 in vitro, floating cell aggregates, called neurospheres, were collected and dissociated with $0.1 \%(\mathrm{w} / \mathrm{v})$ trypsin. Subsequently, dissociated adult cells were maintained and passaged every week. Embryonic neurospheres were passaged every 3-4 d. All of the results presented here were obtained by using the secondary neurosphere cultures.

In some experiments, the following peptide factors were added to the culture medium: mouse sonic hedgehog (Shh) (100-500 ng/ml; Genzyme, Minneapolis, MN), human bone morphogenetic protein 4 (BMP4) (10 ng/ml; Genzyme), all-trans retinoic acid ( $0.5 \mu \mathrm{M}$; Sigma), human brain-derived neurotrophic factor (BDNF) $(50 \mathrm{ng} / \mathrm{ml}$; Sigma), human neurotrophin-3 (NT-3) (50 ng/ml; Sigma), and human glial-derived neurotrophic factor (GDNF) (1 ng/ml; Peprotech, London, UK).

Retrovirus infection. Recombinant retroviruses were used for lineagetracing studies and gene transfer in cultures of adult neural progenitors. The replication-defective recombinant retrovirus vector pMX-IRESEGFP (herein termed pMXIG) expresses green fluorescence protein (GFP) (Morita et al., 2000). To examine the fate of individual neural
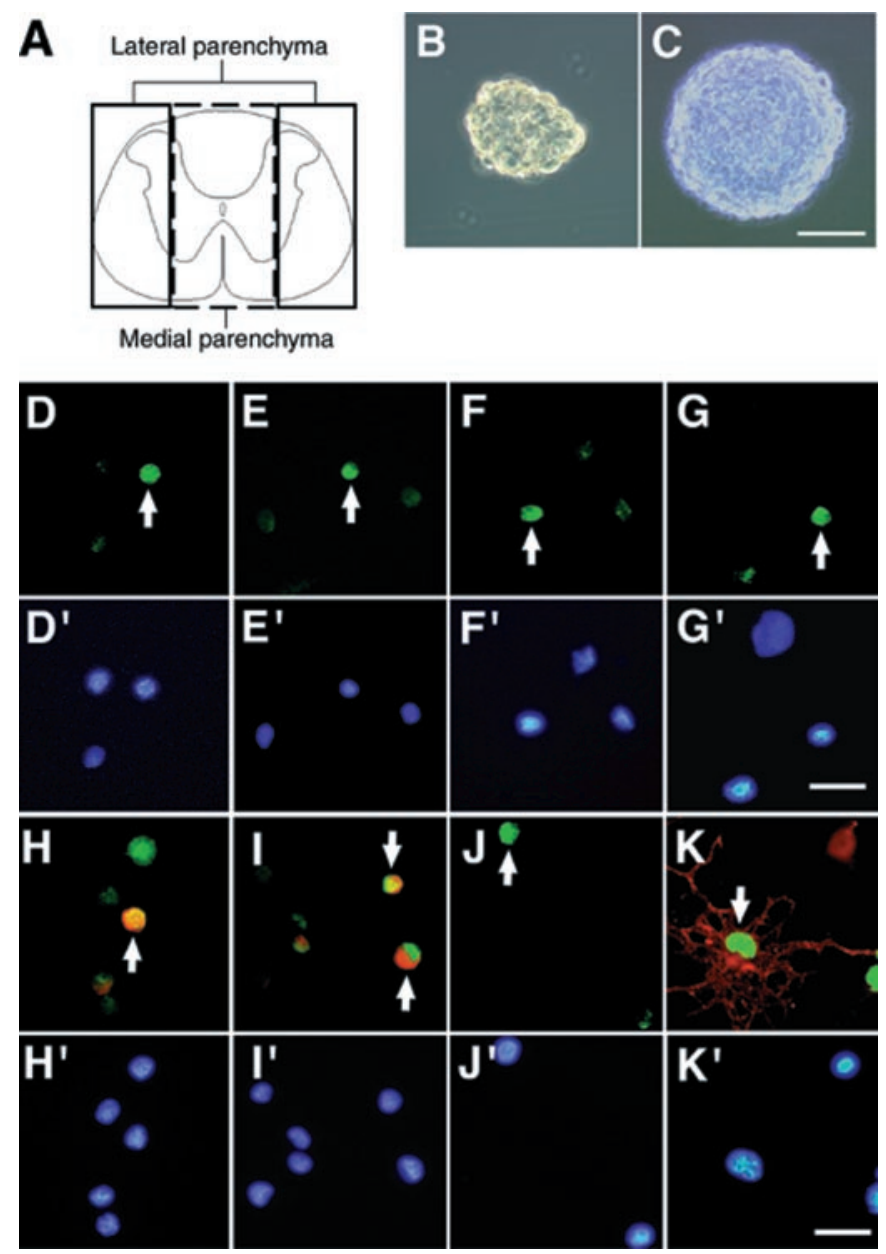

Figure 1. Expression of specific transcription factors in neural progenitors of the adult and embryonic spinal cord in vitro. $A$, Schematic diagram showing tissue preparations of the adult spinal cord. The lateral and medial parts of the parenchyma were separated by using the position of the dorsal horn as a landmark. The solid lines indicate the preparation of lateral parenchyma, whereas the striped lines indicate the medial part. $B$, $C$, Phase-contrast pictures of single neurosphere-like cell aggregates derived from the adult lateral parenchyma $(B)$ and from the E13.5 embryonic spinal cord $(C) . D-K$, Immunofluorescence pictures showing the expression of Pax6 $(D, H), \operatorname{Nkx} 2.2(E, I), \operatorname{Ngn} 2(F, J), \operatorname{HB} 9(G)$, and Olig2 $(K)$ in cultures of embryonic $(D-G)$ and adult $(H-K)$ spinal cord progenitors (green, arrows; $D-F, H-J$, DAP0; $G, K$, DAP2). In $H$ and $I$, Pax6 and Nkx2.2 (green) were double-stained for nestin (red), whereas coexpression of Olig2 ( green) and O4 (red) was shown in K. Pictures in $D^{\prime}-K^{\prime}$ show nuclear staining with bis-benzimide in the same fields shown in $D-K$, respectively. Scale bars: (in $C$ ) $B, C, 50 \mu \mathrm{m}$; (in $G^{\prime}, K^{\prime}$ ) $D-K^{\prime}, 20 \mu \mathrm{m}$.

progenitors, secondary neurospheres were seeded onto poly-D-lysine (PDL) $(100 \mu \mathrm{g} / \mathrm{ml}$; Sigma)-coated chambers and incubated with pMXIG virus in the presence of $4 \mu \mathrm{g} / \mathrm{ml}$ hexadimethrine bromide (polybrene; Sigma) on the day of plating. Infection was performed at low frequency (10-15 GFP-positive clones $/ 10^{4}$ total cells per well and 15-20 GFPpositive clones $/ \mathrm{cm}^{2}$ ) to yield discrete clusters of labeled cells in monolayer culture. During the subsequent culture period, distribution of GFP-labeled cells in each well was monitored under the microscope to confirm the clonality of individual clusters. This method allowed us to identify individual GFP-labeled clusters as clones derived from single progenitors. Four days after infection, the cell-type composition of GFP-positive clones (representing the progeny of single infected cells) was analyzed by immunostaining.

Complementary DNAs encoding truncated forms of mouse Notch1 [termed Notch1-A; amino acid residues 1704-2531 (GenBank accession number Z11886)] and mouse Delta-like 1 [Dll1-A, amino acid residues 
1-582 (GenBank accession number NM007865)], and the full-length rat Ngn2 were engineered by PCR. The resultant cDNA fragments were cloned into pMXIG. The primary neurospheres derived from the whole spinal cord were dissociated by trypsin, and the cells were infected with recombinant viruses. Subsequently, the cells were maintained in floating culture for 1 week. During this culture period, $\sim 5-10 \%$ of the cells expressed GFP. The resultant secondary neurospheres were dissociated by trypsin, seeded onto PDL-coated chambers, and incubated for $2 \mathrm{~d}$ in the growth medium without FGF2 and EGF. The pMXIG virus without cDNA inserts was used as the control.

Spinal cord transection. Adult rats were anesthetized with $50 \mathrm{mg}$ of ketamine (Ketalar, $50 \mathrm{mg} / \mathrm{ml}$; Sankyo Co. Ltd., Tokyo, Japan) and 5 mg of xylazine (Rompun, $20 \mathrm{mg} / \mathrm{ml}$; Bayer, Leverkusen, Germany) per kilogram of body weight. Laminectomy was performed between the T9 and T11 segments, and the spinal cord was transected at the T10 level with microscissors (Miura et al., 2000). 5-Bromo-2'deoxyuridine (BrdU) $(50 \mathrm{mg} / \mathrm{kg}$; Sigma) dissolved in $0.9 \%$ sterile saline was injected intraperitoneally every $2 \mathrm{hr}$. The control rats received BrdU for $48 \mathrm{hr}$ before being killed, whereas injured rats were labeled for a maximum of $3 \mathrm{~d}$ after transection. One to $7 \mathrm{~d}$ after surgery, rats were killed and fixed by intracardial perfusion of $4 \%(\mathrm{w} / \mathrm{v})$ paraformaldehyde (Chiyoda-junyaku, Tokyo, Japan) in PBS. The tissue was cryoprotected with sucrose and embedded into OCT compound (Tissue-Tek, Torrance, CA).

Antibodies and immunostaining. Affinity-purified rabbit polyclonal antibodies (pAbs) against nestin (diluted 1:1000; Nakafuku and Nakamura, 1995), Prox1 (1:2000; Torii et al., 1999), Olig2 (1:3000), Mash1 (1:5000; Takebayashi et al., 2000), and Notch1 (1:2000; Shawber et al., 1996) were described previously. In some experiments, biotinconjugated anti-Olig2 antibody was used for double-staining. AntiNeurogenin2 (Ngn2; 1:5000) and anti-Pax6 (1:1000) rabbit pAbs were prepared by immunization with synthetic oligopeptides that correspond to the N-terminal and $\mathrm{C}$-terminal amino acid sequences of rat Ngn2 and Pax6, respectively. Antibodies against the following antigens were generous gifts: microtubule-associated protein 2 (MAP2) (rabbit pAb; 1:4000; from Dr. Y. Ihara, University of Tokyo, Tokyo, Japan) and the M-phase-specific phosphorylated form of vimentin (pVim) [mouse monoclonal antibody (mAb), clone 4A4; 1:50; from Dr. M. Inagaki, Aichi Cancer Center, Nagoya, Japan (Kamei et al., 1998)]. Mouse mAbs against nestin (Rat401; 1:500), $160 \mathrm{kDa}$ subunit of neurofilament (NF160) (2H3; 1:50), Pax7 (PAX7; 1:100), Nkx2.2 (74.5A5; 1:100), Islet1 (39.4D5; 1:100), Lim1 (4F2; 1:100), Lim3 (67.4E12; 1:100), and HB9 $(81.5 \mathrm{C} 10 ; 1: 100)$ were obtained from the Developmental Studies Hybridoma Bank of the University of Iowa (Iowa City, IA). Other antibodies were purchased from commercial sources: BrdU (mouse mAb; 1:200; Becton Dickinson, Franklin Lakes, NJ), BrdU-peroxidase-conjugated (mouse mAb; 1:5; Roche), NeuroD1 (goat pAb; 1:100; Santa Cruz Biotechnology, Santa Cruz, CA), MAP2 (mouse mAb, clone HM2; 1:100; Sigma), $\beta$-tubulin type III (TuJ1) (mouse mAb; 1:5000; Babco, Richmond, CA), NeuN (mouse mAb; 1:50; Chemicon, Temecula, CA), glial fibrillary acidic protein (GFAP) (mouse mAb, clone G-A-5; 1:1000; Sigma) (rabbit pAb; 1:1000; Chemicon), NG2 (rabbit pAb; 1:2000; Chemicon), O4 (mouse IgM mAb; 1:20; Roche), and choline acetyltransferase (ChAT) (rabbit pAb; 1:1000; Chemicon).

Indirect immunocytochemistry of cultured cells was performed as described previously (Torii et al., 1999). Immunoreactive cells were visualized by staining with appropriate sets of secondary antibodies conjugated with fluorescein isothiocyanate (1:100; Amersham Pharmacia Biotech, Buckinghamshire, UK), Alexa Fluor 488 (1:400; Molecular Probes, Eugene, OR), Texas red (1:100; Amersham Pharmacia Biotech), and aminomethylcoumarine acetate (1:50; Jackson ImmunoResearch, West Grove, PA). To count cell numbers, cell nuclei were stained with 1 $\mu \mathrm{g} / \mathrm{ml}$ bis-benzimide (Molecular Probes). Coronal cryosections (10- $\mu \mathrm{m}-$ thick) of the proximal site of the rostral aspect of the injured spinal cord were subjected to immunostaining. Staining was visualized with a combination of colorimetric substrates for peroxidase (ImmunoPure Cobalt/ Nickel-Enhanced Diaminobenzidine Substrate Kit; Pierce, Rockford, IL) and alkaline phosphate (AP Substrate Kit IV; Vector Laboratories, Burlingame, CA) (Torii et al., 1999). Some sections were counterstained with methyl green before mounting.

Statistical analysis. Quantitative results were expressed as mean $\pm \mathrm{SD}$ $(n=3-5)$ and statistically analyzed by unpaired $t$ test where necessary.

\begin{tabular}{|c|c|c|c|c|}
\hline & \multirow[b]{3}{*}{ Marker } & \multicolumn{3}{|c|}{ Marker-positive cells ( $\%$ of total cells) } \\
\hline & & \multirow[b]{2}{*}{ E13.5 embryo } & \multicolumn{2}{|c|}{ Adult parenchyma } \\
\hline & & & Medial & Lateral \\
\hline \multirow[t]{8}{*}{ DAP0 } & Pax6 & $5.9 \pm 1.1$ & $1.6 \pm 0.2$ & $1.2 \pm 0.2$ \\
\hline & Pax7 & $6.6 \pm 0.6$ & $<0.01$ & $<0.01$ \\
\hline & Nkx2.2 & $2.5 \pm 1.0$ & $12.0 \pm 0.2$ & $11.7 \pm 0.3$ \\
\hline & $\mathrm{Ngn} 2$ & $2.3 \pm 0.5$ & $1.2 \pm 0.0$ & $1.2 \pm 0.1$ \\
\hline & Mash1 & $1.3 \pm 0.1$ & $0.8 \pm 0.1$ & $0.7 \pm 0.1$ \\
\hline & NeuroD1 & $1.8 \pm 0.6$ & $1.4 \pm 0.2$ & $1.1 \pm 0.2$ \\
\hline & Prox1 & $8.8 \pm 1.3$ & $10.2 \pm 0.6$ & $10.6 \pm 0.7$ \\
\hline & Olig2 & $12.5 \pm 1.2$ & $41.3 \pm 3.4$ & $44.8 \pm 2.6$ \\
\hline \multirow[t]{5}{*}{ DAP2 } & MAP2 & $8.5 \pm 0.8$ & $9.7 \pm 1.2$ & $4.9 \pm 0.6$ \\
\hline & Islet1 & $1.2 \pm 0.2$ & $<0.01$ & $<0.01$ \\
\hline & Lim3 & $0.9 \pm 0.2$ & $<0.01$ & $<0.01$ \\
\hline & HB9 & $0.3 \pm 0.1$ & $<0.01$ & $<0.01$ \\
\hline & Lim1 & $1.0 \pm 0.3$ & $<0.01$ & $<0.01$ \\
\hline
\end{tabular}

The secondary neurosphere-forming cells from adults (medial and lateral parenchyma) and E13.5 embryos were dissociated by trypsin and seeded onto PDL-coated chambers. Two hours (DAP0) and $2 \mathrm{~d}$ (DAP2) after plating, the cells were subjected to immunostaining. The percentages of immunopositive cells in the total cells are shown as mean $\pm \operatorname{SD}(n=3-5)$.

\section{RESULTS \\ Expression of specific transcription factors in adult progenitors in vitro}

The developing spinal cord is composed of multiple types of progenitors, and they express many different regulatory molecules (Tanabe and Jessell, 1996; Rao, 1999). Little attention has been paid, however, to the heterogeneity of adult progenitors at the molecular level. We first addressed this issue by examining the expression of various regulatory molecules in vitro. Tissues from the adult and embryonic spinal cord were subjected to primary cultures, and proliferative progenitors were enriched in the presence of FGF2 and EGF. The parenchyma of the adult spinal cord was divided into the medial and lateral parts to characterize potential regional heterogeneity (Fig. $1 A$ ). Proliferative cells were recovered as cell aggregates, with a morphology resembling that of so-called neurospheres (Fig. 1B,C) (Gritti et al., 1996; Weiss et al., 1996). These neurosphere-forming cells could be maintained by repeated passages for at least 8 weeks (data not shown). We used the secondary neurospheres as the source of proliferative progenitors.

Pax6, Pax7, and Nkx2.2 are homeodomain transcription factors that define the regional specificity of neural progenitors in the developing spinal cord (Tanabe and Jessell, 1996). The expression of these molecules was recapitulated in a subset of embryonic progenitors (Fig. 1D,E, Table 1). Pax6-positive $\left(\mathrm{Pax}^{+}\right)$and $\mathrm{Nkx} 2.2^{+}$cells were also detected in cultures of adult progenitors (Fig. 1H,I, Table 1). Although few cells expressed Pax7 in separate cultures of the medial and lateral parenchyma, some $\operatorname{Pax} 7^{+}$ cells could be detected in cultures of the whole spinal cord (data not shown).

$\mathrm{Nkx} 2.2$ is expressed not only in multipotential progenitors but also in a subset of oligodendrocytes (Xu et al., 2000). Consistently, a fraction $(\sim 20 \%)$ of $\mathrm{Nkx} 2.2^{+}$cells expressed NG2, a marker for adult glial progenitors (Dawson et al., 2000; Horner et al., 2000; McTigue et al., 2001) (data not shown). Other than these glial cells, many Pax6 ${ }^{+}$and Nkx2.2 $2^{+}$cells in 

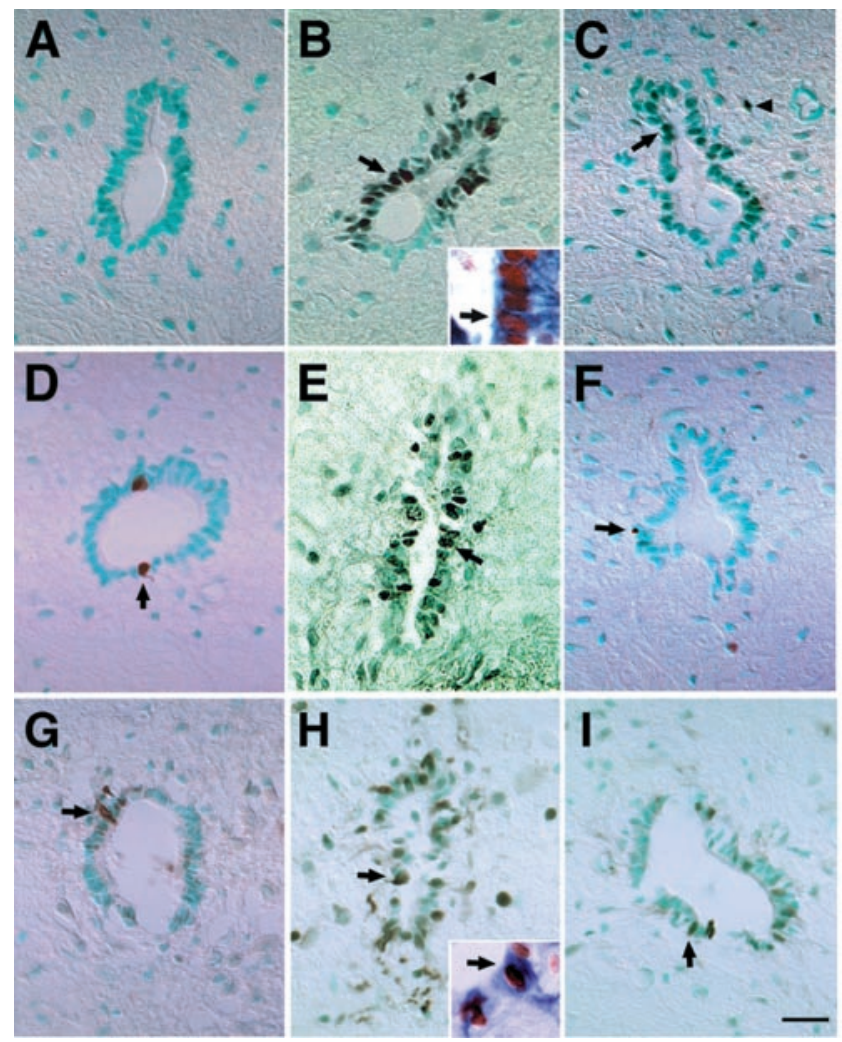

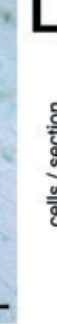

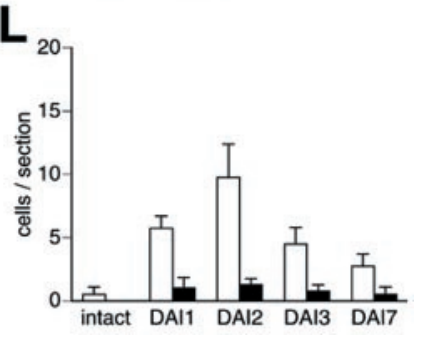

Figure 2. Induction of Pax6 and increase in cell division in the ependymal layer after injury. $A-I$, Immunostaining of the periventricular region with anti-Pax6 $(A-C)$, anti$\operatorname{BrdU}(D-F)$, and anti-pVim $(G-I)$ antibodies (brown). The expression of Pax6 was detected in the ependymal layer of the injured (DAI2, $B$; DAI7, $C$ ), but not intact $(A)$, spinal cord. $\mathrm{BrdU}^{+}$and $\mathrm{pVim}^{+}$ ependymal cells were very rare in the intact spinal cord $(D, G)$. Their numbers transiently increased at DAI2 $(E, H)$ and returned to the normal levels at DAI7 $(F, I)$. Arrows in $B-I$ indicate immunopositive cells, and the arrowheads in $B$ and $C$ show $\mathrm{Pax}^{+}$cells in the periventricular region. The insets in $B$ and $H$ show Pax6 (brown)nestin (blue) and BrdU (brown)-pVim (blue) double-positive cells (arrows), respectively. Scale bar (in $I$ ), $50 \mu \mathrm{m}$. $J-L$, Parallel changes of the expression of Pax6 and proliferative response in the ependymal layer. Changes of the numbers of $\mathrm{Pax}^{+}(J), \mathrm{BrdU}^{+}(K)$, and $\mathrm{pVim}^{+}(L)$ ependymal cells per $10 \mu \mathrm{m}$ transverse section, proximal ( $<1 \mathrm{~mm}$; open bars $)$ and distal ( $>2 \mathrm{~mm}$; filled bars) to the lesion, were quantified. The results are shown as mean $\pm \mathrm{SD}(n=3-5)$. adult neurospheres ( $\sim 65$ and $50 \%$, respectively) expressed nestin (Fig. 1H,I). Nestin is abundantly expressed in, but not specific for, undifferentiated progenitors (Lendahl et al., 1990). However, only $\sim 5 \%$ of nestin ${ }^{+}$cells coexpressed markers for neurons and glia, such as TuJ1, MAP2, GFAP, NG2, and O4, in our cultures (data not shown). Thus, the properties of $\mathrm{Pax}^{+}$and $\mathrm{Nkx} 2.2^{+}$cells in adult cultures resembled those of embryonic neural progenitors.

In the developing spinal cord, the bHLH-type transcription factors Ngn2 and Mash1 are expressed in subsets of neural progenitors, whereas NeuroD1 and Prox1 are specifically expressed in differentiating neurons (Lee et al., 1995; Torii et al., 1999; Nieto et al., 2001). Cells expressing these molecules were detected in both adult and embryonic neurospheres (Fig. $1 F, J$, Table 1). The bHLH factor Olig2 is expressed in cells of the oligodendrocyte lineage (Lu et al., 2000; Takebayashi et al., 2000; Zhou et al., 2000). Many adult cells expressing Olig2 were detected, and the majority of $\mathrm{O}_{4}{ }^{+}$oligodendrocytes were Olig2 ${ }^{+}$ (Fig. $1 K$ ). Cells expressing the above molecules could be identified in cultures of both the medial and lateral parenchyma. These results support the idea that adult neurosphere-forming cells are composed of heterogeneous progenitor subtypes at the molecular level.

\section{Inability of adult progenitors to generate specific neuronal subtypes}

In the developing CNS, distinct progenitors generate different subtypes of neurons (Tanabe and Jessell, 1996). Accordingly, multiple neuronal subtypes have been identified in cultures of the embryonic spinal cord (Richards et al., 1995; Dutton et al., 1998; Kalyani et al., 1998; Chow et al., 2000). Here we examined the specificity of neuronal subtypes in cultures of adult progenitors at the molecular level. Islet1, Lim3, and HB9 are specifically expressed in spinal motoneurons, whereas Lim1 is a marker for a subtype of interneurons (Tanabe and Jessell, 1996). Cells expressing these markers were detected in cultures of embryonic progenitors (Fig. 1G, Table 1). In contrast, no expression of these markers could be detected in adult neurospheres, although significant fractions of the cells differentiated into $\mathrm{MAP}^{+}{ }^{+}$neurons (Table 1). Neuronal differentiation was also detected by staining of TuJ1, NF160, and NeuN (data not shown). Various extracellular stimuli, such as Shh, BMP4, and retinoic acid, regulate the differentiation of specific neurons during development (Tanabe and Jessell, 1996). However, no expression of specific molecular markers was induced by these soluble factors in adult cultures. The neurotrophic factors BDNF, NT-3, and GDNF also failed to induce cells to express markers for motoneurons and interneurons. The expression of ChAT, a marker for motoneurons, could not be detected in cultures of adult progenitors (data not shown). Thus, unlike their embryonic counterparts, progenitors in the adult spinal cord appear to lack the ability to generate specific neuronal subtypes in vitro.

\section{Expression of specific transcription factors in vivo}

The precise locations of distinct progenitor subtypes in vivo remain unknown. We next attempted to address this issue by using specific molecular markers.

In the intact spinal cord, ependymal cells expressed none of the molecular markers described above at detectable levels. Cell divisions of ependymal cells are also very rare (Fig. 2A,D, $G$ ). However, after transection injury, many ependymal cells began to express Pax6 (Fig. 2B). Concomitantly, labeling with BrdU detected dividing ependymal cells (Fig. 2E) (Beattie et al., 1997; Johansson et al., 1999; Namiki and Tator 1999). The expression of pVim (Kamei et al., 1998) also indicated cell divisions in the ependymal layer (Fig. $2 H$ ). Increases in the numbers of Pax6 ${ }^{+}$, $\mathrm{BrdU}^{+}$, and $\mathrm{pVim}^{+}$cells were detected $1 \mathrm{~d}$ after injury (DAI1) and were most prominent at DAI2-DAI3 (Fig. 2J-L). The in- 
duction of Pax6 and proliferation of ependymal cells were more prominent proximal $(<1 \mathrm{~mm})$ than distal $(>2 \mathrm{~mm})$ to the lesion (Fig. $2 J-L)$. In addition, both changes were transient, almost disappearing by DAI7 (Fig. $2 C, F, I$ ). Thus, the expression of Pax6 closely paralleled the proliferative response of ependymal cells. A few Pax6 ${ }^{+}$cells were also detectable adjacent to the ependyma (Fig. 2B,C, arrowheads). These cells may reflect migration of dividing ependymal cells, as suggested in previous studies (Johansson et al., 1999; Namiki and Tator 1999). As shown previously (Frisen et al., 1995; Johansson et al., 1999; Namiki and Tator 1999), injury enhanced the expression of nestin in the ependymal layer, and Pax6 ${ }^{+}$ependymal cells coexpressed nestin (Fig. 2B, inset). However, no expression of transcription factors other than Pax6, including Pax7, Nkx2.2, Ngn2, Mash1, NeuroD1, Prox1, and Olig2 was detected in, or adjacent to, the ependymal layer (data not shown).

As described above, cells expressing various regulatory molecules could be detected in cultures of both the medial and lateral parts of the parenchyma. Thus, we next examined whether any parenchymal cells express specific transcription factors in vivo.

Olig2 and Nkx2.2 were expressed in subsets of glia and their progenitors in vitro. $\mathrm{NG}_{2}{ }^{+}$glial progenitors remain in the adult spinal cord and proliferate in response to injury (Dawson et al., 2000; Horner et al., 2000; McTigue et al., 2001). Consistently, some Olig2 ${ }^{+}$and $\mathrm{Nkx}_{2} .2^{+}$cells became $\mathrm{BrdU}^{+}$in the lesioned parenchyma (Fig. $3 A, C$ ), and $15-20 \%$ of these cells were $\mathrm{NG}^{+}$ (Fig. $3 B, D)$. Only a minor percentage $(\sim 5 \%)$ of the cells coexpressed Nkx2.2 and Olig2 (Fig. 3D, inset), suggesting that they may constitute distinct populations among $\mathrm{NG}^{+}$cells in vivo. However, the majority of $\mathrm{Nkx} 2.2^{+}$cells in the lesioned parenchyma were $\mathrm{NG} 2$ negative $\left(\mathrm{NG} 2^{-}\right)$, and a significant fraction $(\sim 10 \%)$ of $\mathrm{Nkx} 2.2^{+}$cells coexpressed nestin (Fig. 3E). Furthermore, $\mathrm{Pax}^{+}{ }^{+}$and $\mathrm{Pax} 7^{+}$cells, which were not detectable in intact tissue, emerged after injury. Some of these cells became $\mathrm{BrdU}^{+}$ (Fig. $3 F$ and data not shown), and the majority ( $\sim 90 \%)$ were nestin $^{+}$(Fig. 3G,H). The expression of nestin is known to be induced in both astrocytes and $\mathrm{NG} 2{ }^{+}$cells in the injured spinal cord (Frisen et al., 1995; Namiki and Tator, 1999). However, some of the above transcription factor-expressing cells did not express markers for neurons or glia, such as TuJ1, MAP2, GFAP, and NG2.

We further examined the spatial distribution patterns of transcription factor-expressing cells. Many $\mathrm{Nkx} 2.2^{+}$cells resided in the intact parenchyma (71.7 \pm 7.6 cells per section; $n=3)$, and their number increased at DAI2 (173.7 \pm 14.8 cells per section; $n=3)$. The $\mathrm{NG} 2^{-}$population among $\mathrm{Nkx} 2.2^{+}$cells was mainly present in the white matter but became detectable throughout the spinal cord after injury (Fig. 3I,J). A similar distribution pattern was found for $\mathrm{Nkx}_{2} .2^{+}$-nestin ${ }^{+}$cells (Fig. $3 K$ ). In contrast, $\mathrm{Pax}^{+}$cells were specifically detected in the lateral aspect of the parenchyma at DAI2 (Fig. $3 L)(16.3 \pm 3.1$ cells per section; $n=$ $3)$. These Pax6 ${ }^{+}$cells emerged distant from the central canal. Thus, it is unlikely that migration of ependymal cells could account for all, if any, of these parenchymal Pax6 ${ }^{+}$cells. One day later (DAI3), the number of $\mathrm{Pax}^{+}$cells significantly increased $(43.0 \pm 2.0$ cells per section; $n=3)$, and they became detectable in the medial parenchyma (Fig. $3 M$ ). Unlike Pax6 ${ }^{+}$cells, Pax $7^{+}$ cells was specifically detected around the dorsal horn (Fig. 3O). Their number and distribution pattern did not significantly change between DAI2 and DAI3 (Fig. 3P) $(23.0 \pm 5.0$ and $29.3 \pm$ 1.2 cells per section at DAI2 and DAI3, respectively; $n=3$ ). Later after injury (DAI7), a few cells expressing Pax6 and Pax7
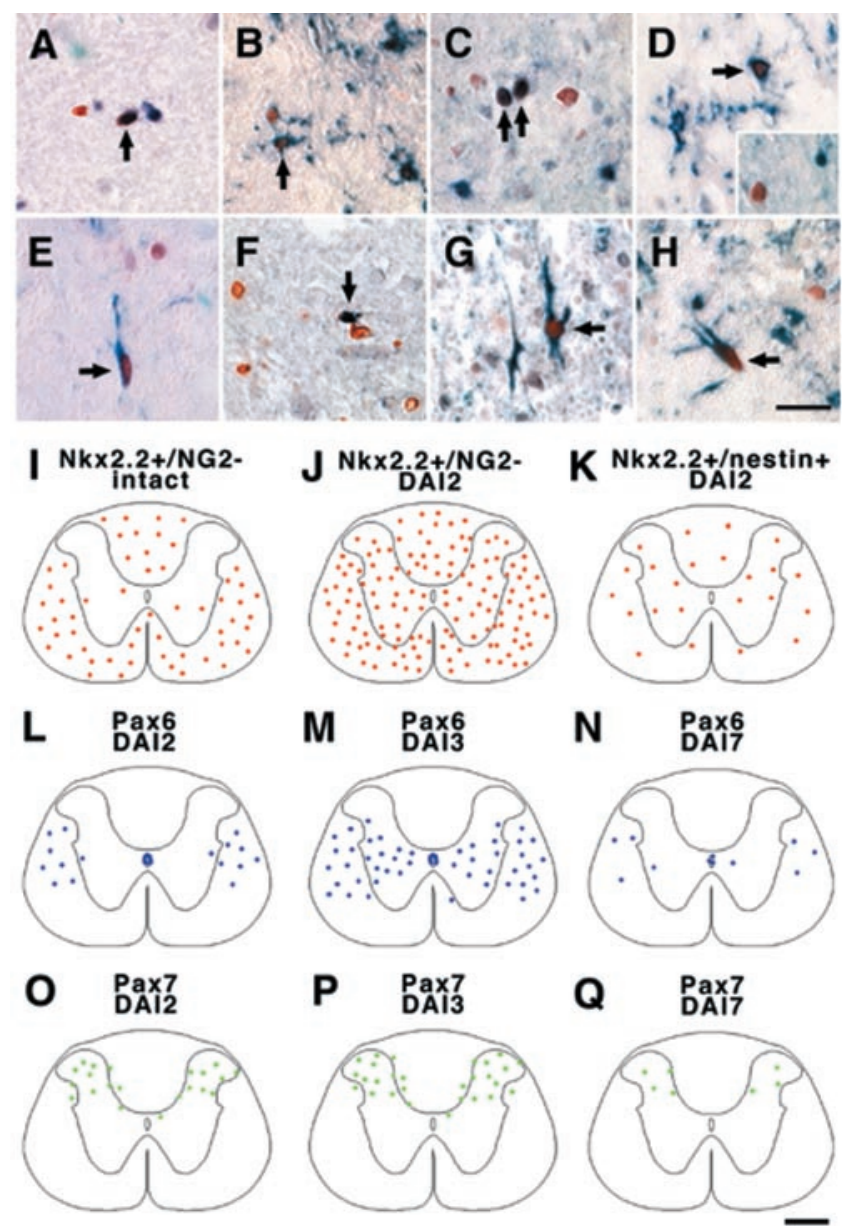

Figure 3. Emergence of cells expressing various transcription factors in the lesioned parenchyma. $A-H$, The parenchyma of the injured spinal cord $(A-E, G, H$, DAI2; $F, \mathrm{DAI} 3)$ was stained with antibodies against Olig2 $(A, B), \operatorname{Nkx2.2}(C-E)$, Pax6 $(F, G)$, and Pax7 $(H)$. The cells expressing specific transcription factors $(A, C, F$, blue; $B, D, E, G, H$, brown $)$ were double-stained with anti-BrdU $(A, C, F$, brown), anti-NG2 ( $B$, $D$, blue $)$, and anti-nestin $(E, G, H$, blue $)$ antibodies. The arrows indicate double-positive cells. The inset in $D$ indicates that $\mathrm{Nkx} 2.2^{+}$(brown) and Olig2 ${ }^{+}$(blue) cells are distinct populations. $I-Q$, Distribution of Nkx2.2 $2^{+}-\mathrm{NG}^{-}(I, J), \mathrm{Nkx} 2.2^{+}{ }^{-}$nestin $^{+}(K), \mathrm{Pax}^{+}{ }^{-}(L-N)$, and $\mathrm{Pax}^{+}$ $(O-Q)$ cells in the spinal cord: $I$, the intact spinal cord; $J-L, O$, DAI2; $M$, $P$, DAI3; $N, Q$, DAI7. Each $d o t$ indicates the position of a cell with the respective antigenic phenotype in a representative section. Essentially identical results were obtained in three independent sections. Scale bars: (in $H$ ) $A-H, 20 \mu \mathrm{m}$; (in $Q$ ) $I-Q, 500 \mu \mathrm{m}$.

remained, but their numbers significantly decreased (Fig. $3 N, Q$ ) $(7.0 \pm 1.0$ and $6.3 \pm 0.6$ cells per section for Pax6 and Pax7, respectively; $n=3$ ). The number of $\mathrm{Nkx} 2.2^{+}$cells also decreased at DAI7 (124.7 \pm 7.5 cells per section; $n=3)$. These results demonstrated that cells expressing specific transcription factors emerge in vivo in response to injury.

\section{Inhibition of neurogenesis by Notch signaling}

The above results suggest that endogenous progenitors can respond to injury in vivo. Nevertheless, production of new neurons has not been detected in the injured spinal cord (Johansson et al., 1999; Namiki and Tator 1999). $\mathrm{No} \mathrm{BrdU}^{+}$cells that coexpressed the neuronal marker TuJ1 could be detected in our injury model as well (data not shown). This is in clear contrast to the fact that adult progenitors can generate new neurons when isolated free 
from their in vivo environment and cultured in vitro. Thus, a next important issue is to elucidate the mechanisms for this restriction in vivo.

An important clue to address this issue at the molecular level is the expression of bHLH factors in adult progenitors. During development, various bHLH factors, such as Ngn2, Mash1, and NeuroD1, play essential roles in generating neurons from multipotential progenitors (Ma et al., 1996; Torii et al., 1999; Nieto et al., 2001; Sun et al., 2001). As described above, adult progenitors could also express these factors in vitro. In contrast, we found that no cells expressing these factors emerged in the lesioned spinal cord (data not shown). Thus, the expression of neurogenic bHLH factors in vivo appears to be suppressed by certain environmental signals, which could account for the restricted neurogenesis in injured tissue. One of the possible mechanisms for this suppression is the signaling through the cell-surface receptor Notch. The Notch receptor mediates local environmental signals that inhibit differentiation of neurons during development (Nye et al., 1994; Wang and Barres, 2000), and this action of Notch is attributable to the inhibition of some bHLH factors, including Ngn2 and Mash1 (Ma et al., 1996; de la Pompa et al., 1997). Thus, we sought to examine whether Notch signaling plays any role in regulating neural progenitors in the adult spinal cord.

First, we examined the expression of Notch1, a member of the Notch receptor family expressed in the developing spinal cord (Weinmaster, 1997). Notch1 expression has been detected in the ependymal layer in the forebrain (Johansson et al., 1999). In the adult spinal cord, the expression of Notch1 was detected not only in the ependyma but also in the parenchyma (Fig. $4 A$ and data not shown). Importantly, its expression level was significantly enhanced in the injured tissue, and strong staining signals were detected in cell nuclei (Fig. $4 B, D, E$, arrows). It has been shown that the nuclear localization of Notch1 is indicative of activation of Notch signaling (Sestan et al., 1999; Redmond et al., 2000). In the lesioned parenchyma, $10.7 \pm 1.4 \%(n=3)$ of the total $\mathrm{BrdU}^{+}$ cells detected at DAI2 were immunopositive for Notch1 (Fig. 4D, arrow), and these Notch $1^{+}-\mathrm{BrdU}^{+}$cells were scattered in the spinal cord (Fig. 4F). Many of these Notch $1^{+}$cells coexpressed nestin (Fig. 4E). However, the enhancement of Notch1 expression was transient and reduced at DAI7 in both the ependyma and parenchyma (Fig. $4 C$ and data not shown). The expression of Nocth1 was also detected in neurosphere cultures of adult progenitors; $11.0 \pm 0.9 \%(n=3)$ of the cells in neurospheres were Notch $1^{+}$, and many of them coexpressed nestin (Fig. 4G). These results support the idea that Notch signaling operates in vivo in the adult spinal cord.

We next examined the role of Notch signaling in vitro by genetically manipulating adult progenitors with the GFPexpressing recombinant retrovirus pMXIG (Morita et al., 2000). Retrovirus preferentially infects actively dividing cells, and therefore a recombinant virus-mediated gene expression system allowed us to examine the effects of genes of interest on proliferative progenitors. When neurosphere-forming cells were plated on PDL-coated chambers and subsequently infected with pMXIG virus at a low frequency, clonal progeny of individual progenitors could be identified as discrete clusters of GFP-expressing cells (for details, see Materials and Methods). Analyses of the cell-type composition of these $\mathrm{GFP}^{+}$clones demonstrated that $\sim 5 \%$ of progenitors were bipotential, generating both $\mathrm{MAP}^{+}$neurons and GFAP $^{+}$astrocytes (Fig. $4 M$ ). Other clones, $\sim 25 \%$ of the total clones examined, generated only either neurons or astrocytes, and the remaining clones contained only nestin ${ }^{+}$cells (data

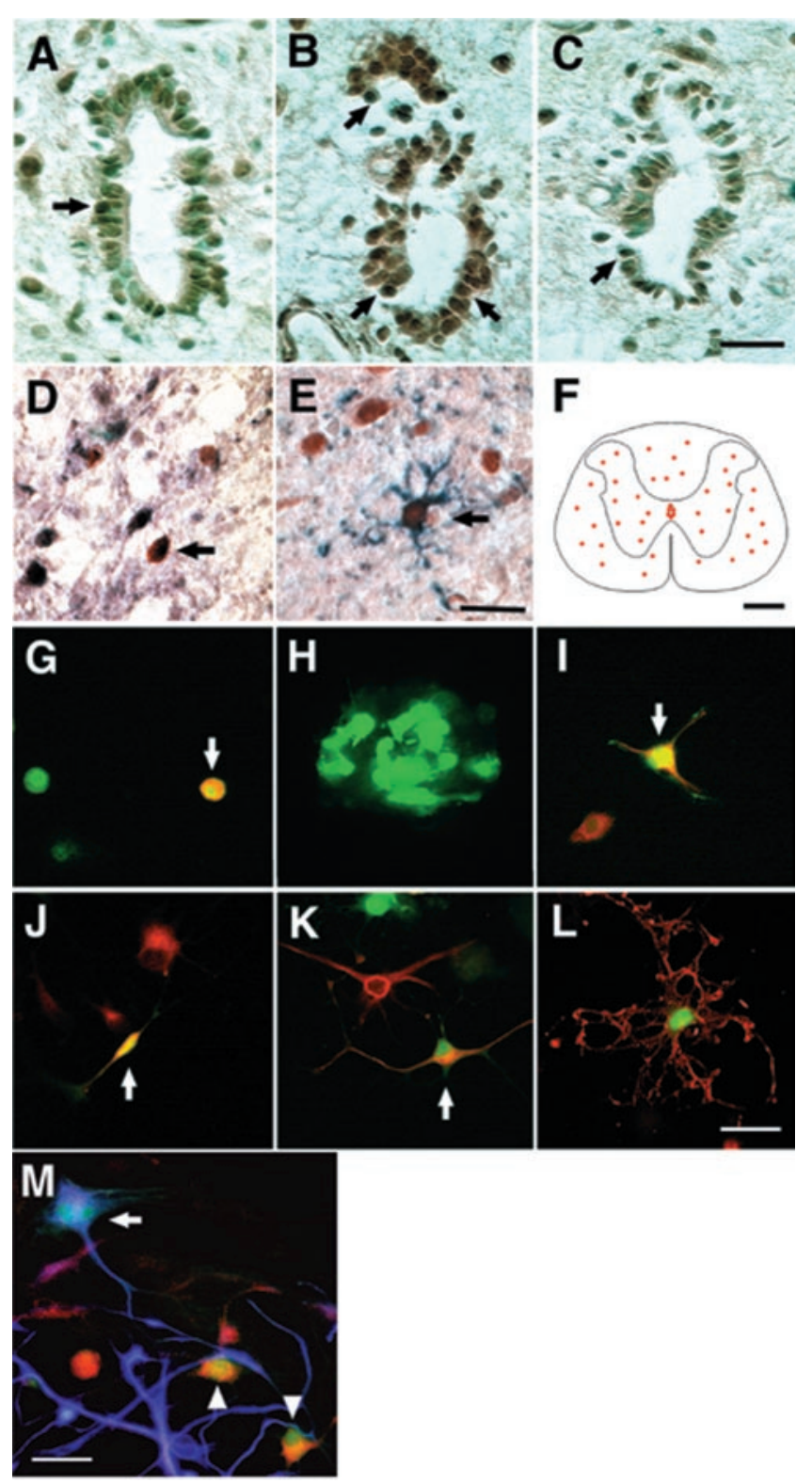

Figure 4. Involvement of Notch signaling in the regulation of adult neural progenitors. $A-F$, The expression of Notch1 in vivo. Notch1 ${ }^{+}$ ependymal cells (brown, arrows) are present in the intact $(A)$ and injured (DAI2, $B$; DAI7, $C$ ) spinal cord. $D$ and $E$ show Notch1 (blue)-BrdU (brown) $(D$, arrow) and Notch1 (brown)-nestin (blue) $(E$, arrow) doublepositive cells, respectively, in the lesioned parenchyma (DAI2). $F$ depicts the distribution of Notch $1^{+}-\mathrm{BrdU}^{+}$cells in the injured spinal cord as shown in Figure 3I-Q. G, The expression of Notch1 (green) in nestin ${ }^{+}$ (red) cells (arrow) in cultures of adult progenitors. H-M, Retrovirusmediated gene expression in adult neural progenitors in vitro. $H$ shows pMXIG retrovirus-directed expression of GFP (green) in adult neurosphere-forming cells. In $I-L$, GFP-labeled progeny was doublestained with nestin $(I), \mathrm{TuJ} 1(J)$, GFAP $(K)$, and $\mathrm{O} 4(L)$ (red, arrows) in monolayer cultures. In $M$, clonal progeny of a single GFP (green)-labeled progenitor was stained with MAP2 (red) and GFAP (blue). This clonal cluster of $\mathrm{GFP}^{+}$cells contained both $\mathrm{MAP}^{+}$neurons (arrowheads) and GFAP $^{+}$astrocytes (arrow). Scale bars: (in $C$ ) $A-C, 50 \mu \mathrm{m}$; (in $E, L, M$ ) $D, E, G-M, 20 \mu \mathrm{m} ; F, 500 \mu \mathrm{m}$.

not shown). Consequently, when adult progenitors were infected as a mixture (Fig. $4 H$ ), 2 and $28 \%$ of the total $\mathrm{GFP}^{+}$progeny differentiated into neurons and glia, respectively (Fig. 4J-L), whereas $21 \%$ remained nestin ${ }^{+}$(Fig. 4I, Table 2 ). Approximately 


\begin{tabular}{|c|c|c|c|c|}
\hline \multirow[b]{2}{*}{ Marker } & \multicolumn{4}{|c|}{ Marker-positive cells ( $\%$ of total $\mathrm{GFP}^{+}$cells) } \\
\hline & Control & Notch1-A & Dll1-A & Ngn2 \\
\hline Nestin & $20.5 \pm 2.3$ & $82.7 \pm 6.2^{*}$ & $6.9 \pm 2.9^{*}$ & $10.4 \pm 2.6^{*}$ \\
\hline TuJ1 & $1.7 \pm 0.3$ & $0.5 \pm 0.4^{*}$ & $4.1 \pm 0.8^{*}$ & $23.9 \pm 1.7^{*}$ \\
\hline GFAP & $12.8 \pm 2.0$ & $2.3 \pm 0.4^{*}$ & $3.3 \pm 1.4^{*}$ & $11.2 \pm 1.9$ \\
\hline $\mathrm{O} 4$ & $15.6 \pm 2.5$ & $4.4 \pm 1.5^{*}$ & $16.1 \pm 2.8$ & $13.6 \pm 1.0$ \\
\hline
\end{tabular}

The primary neurosphere-forming cells were infected with recombinant pMXIG retroviruses. The resultant secondary neurospheres were dissociated by trypsin, seeded onto PDL-coated chambers, and cultured in the growth medium without FGF2 and EGF. Two days after plating, the cell-type composition of $\mathrm{GFP}^{+}$cells (representing the progeny of infected cells) was analyzed by immunostaining. The pMXIG virus without cDNA insert was used as the control. The percentages of immunopositive cells in the total $\mathrm{GFP}^{+}$cells are shown as mean $\pm \mathrm{SD}(n=3-4)$. $\left({ }^{*} p<0.05\right.$ when compared with the infection with the control virus.)

half of the $\mathrm{GFP}^{+}$cells expressed neither nestin nor neuronalglial cell markers, which probably included transient progenitor populations that expressed various regulatory molecules, such as Ngn2 and Mash1 as described above. Thus, in culture of adult progenitors, not all cells fully differentiated into neurons or glia as described in previous studies (Gritti et al., 1996; Weiss et al., 1996).

To manipulate Notch signaling in adult progenitors, we designed two recombinant retroviruses. Notch1-A is a truncated form of the Nocth1 receptor, which lacks its large extracellular domain and thereby exhibits a ligand-independent signaling activity (Weinmaster, 1997). Dll1 is one of the ligands for the Notch1 receptor. Its truncated fragment termed Dll1-A, in which most of the intracellular domain is deleted, acts as a dominantnegative form and inhibits ligand-dependent activation of Notch signaling (Weinmaster, 1997). Complementary DNAs encoding Notch1-A and Dll1-A were cloned into pMXIG, and expressed in adult neurospheres. Subsequently, spheres were dissociated and plated on monolayer to induce differentiation of neurons and glia.

When the cells were infected with Notch1-A virus, the percentages of both neurons and glia among the total $\mathrm{GFP}^{+}$cells became significantly lower than the control levels, and instead, $>80 \%$ of the cells remained nestin ${ }^{+}$(Table 2). As described above, the majority of nestin ${ }^{+}$cells did not coexpress markers for neurons or glia under our culture conditions, and hence nestin ${ }^{+}-\mathrm{GFP}^{+}$cells in Notch1-A virus-infected cultures displayed the properties of undifferentiated progenitors. Thus, constitutive activation of Notch signaling appeared to keep adult progenitors undifferentiated, thereby inhibiting differentiation of both neurons and glia.

Conversely, infection with Dll1-A virus, which is thought to inhibit endogenous Notch signaling, significantly increased the percentage of $\mathrm{TuJ}^{+}{ }^{+}$neurons (Table 2). In this respect, Dll1-A had an effect opposite to that of Nocth1-A, supporting the idea that Notch signals inhibit neurogenesis in adult progenitors. Interestingly, the fraction of $\mathrm{GFAP}^{+}$astrocytes among the total Dll1-A-infected progeny was significantly decreased compared with that in the control virus-infected culture. Although Notch is also implicated in differentiation of oligodendrocytes (Wang et al., 1998), the percentage of oligodendrocytes remained unchanged in our cultures.

These results demonstrated that activation and inhibition of Notch signaling selectively decrease the percentage of astrocytes. This apparent discrepancy can be explained by the idea that Notch signaling regulates the differentiation of adult progenitors at two distinct steps. If Notch signals could block the differentiation of progenitors before a step of lineage commitment, generation of both neurons and glia might be inhibited. Such an early differentiation step of multipotential progenitors has been delineated by the expression of neurogenic bHLH factors, such as Ngn2 and Mash1 (Torii et al., 1999; Nieto et al., 2001). Consistent with this idea, Notch1-A decreased the percentage of $\mathrm{Ngn} 2{ }^{+}$cells $\left(1.2 \pm 0.1\right.$ and $0.4 \pm 0.2 \%$ of the total $\mathrm{GFP}^{+}$cells in control and Notch1A virus-infected cultures, respectively, at DAP0; $n=3$; $p<0.01)$, and conversely, Dll1-A increased the fraction of $\mathrm{Ngn}^{+}$ cells $(3.3 \pm 0.4 \% ; n=4 ; p<0.01)$ in culture of adult progenitors. In addition, recent studies have shown that Notch signaling also plays a role in a subsequent lineage-commitment step. At this late step, activated Notch1 has been proposed to promote the generation of astrocytes at the expense of neurons (Chambers et al., 2001; Tanigaki et al., 2001). Our data are consistent with this idea in that Dll1-A probably attenuates Notch signaling at both early and late steps, and therefore the final outcome of its effect is an increase in the fraction of neurons with a concomitant decrease in that of astrocytes. Similar effects of Notch1-A and Dll1-A viruses were observed in culture of embryonic progenitors (data not shown), suggesting that the mode of action of Notch signaling is common for adult and embryonic progenitors.

The above results collectively demonstrated that Notch signaling plays an important role in regulating neurogenesis from adult progenitors. We noticed, however, that the net production of new neurons was still low ( $<5 \%$ of the total progeny), even when Notch signals were attenuated by Dll1-A. This weak effect may be attributable to incomplete block of Notch signaling by Dll1-A, or alternatively, additional mechanisms may also limit the neurogenic potential of adult progenitors. In line with the latter idea, infection of Dll1-A virus markedly decreased the percentage of nestin $^{+}$cells, but this decrease did not lead to a comparable increase in the percentage of differentiated neurons. Thus, the majority of adult progenitors could not fully differentiate into neurons or astrocytes, although they lost the expression of nestin. This limited differentiation of adult progenitors could be related to the fact that the percentage of cells expressing neurogenic bHLH factors was low in culture of adult progenitors.

Thus, we next asked whether forced expression of Ngn2 could augment the neurogenic potential of adult progenitors. As expected, Ngn2 had a potent neurogenic activity, and infection with Ngn2 virus led to a marked ( $>10$-fold) increase in the percentage of neurons among the total $\mathrm{GFP}^{+}$progeny (Table 2 ). The percentages of astrocytes and oligodendrocytes remained unchanged in Ngn2 virus-infected cultures. Thus, Ngn2 selectively stimulated the generation of neurons from adult neural progenitors. Sun et al. (2001) have reported recently that the Ngn2-related bHLH factor Ngn1 also promotes neurogenesis from embryonic progenitors.

These results of in vitro studies, together with the specific expression of Notch1 in vivo, suggest that Notch signaling is one of the mechanisms that restrict production of new neurons in the injured spinal cord. Furthermore, the limited ability to express neurogenic bHLH factors could also account, at least in part, for the restricted neurogenic potential of adult neural progenitors.

\section{DISCUSSION}

\section{Molecular properties of adult neural progenitors}

Here we demonstrated that neural progenitors from the adult and embryonic spinal cord express many common transcription factors in vitro. These molecules regulate multiple aspects of neuro- 
genesis during development. Pax6, Pax7, and Nkx2.2 play important roles in specifying regional identity of progenitors (Tanabe and Jessell, 1996), whereas Ngn2, Mash1, NeuroD1, Prox1, and Olig2 regulate differentiation of neurons and glia (Lee et al., 1995; Ma et al., 1996; Torii et al., 1999; Nieto et al., 2001). Thus, our results suggest the common control mechanisms for adult and embryonic progenitors.

Neural stem cells are present in both the adult and embryonic spinal cord (Weiss et al., 1996; Kalyani et al., 1997; Johansson et al., 1999; Shihabuddin et al., 2000). We also identified bipotential progenitors in our cultures, although it was not determined whether these cells possessed the properties of bona fide stem cells. In addition to these multipotential progenitors, the embryonic spinal cord contains multiple progenitor subtypes (Rao, 1999), and they express distinct regulatory molecules in vivo (Tanabe and Jessell, 1996). Such specific gene expression in vivo can be recapitulated in vitro (Nakagawa et al., 1996; Zappone et al., 2000). Thus, our results suggests that the adult spinal cord also contains many distinct progenitor subtypes. Such heterogeneity of adult progenitors has been suggested in previous studies (Kehl et al., 1997; Shihabuddin et al., 1997; Horner et al., 2000), and our results support this idea at the molecular level.

Despite such a similarity, we also found an important difference between the properties of adult and embryonic progenitors. During development, distinct progenitor subtypes give rise to different neuronal subtypes (Tanabe and Jessell, 1996). In contrast, progenitors in the adult spinal cord did not generate neurons expressing specific molecular markers in vitro. Extracellular signals acting during development, such as Shh, BMP, and retinoic acid, did not induce specific neurons. A recent study, however, has shown that adult progenitors can generate some specific neurons when exposed to distinct environments in vivo (Shihabuddin et al., 2000). Thus, certain extrinsic cues may regulate their properties, although the nature of such cues remains unknown. Additional studies are needed to explore the mechanisms underlying the generation of specific neuronal subtypes from adult progenitors.

\section{Expression of specific transcription factors in vivo in the adult spinal cord}

The heterogeneity of adult progenitors in vivo still remains elusive. We attempted to address this issue by using specific molecular markers. We detected significant numbers of $\mathrm{Pax} 6^{+}, \mathrm{Pax} 7^{+}$, and $\mathrm{Nkx} 2.2^{+}$cells in the injured spinal cord. These cells were distributed in distinct patterns in the lesioned spinal cord. Such differential patterns may suggest that distinct cell types reside at different locations. Alternatively, some dormant cells may be scattered in the intact spinal cord, and they may express specific genes depending on their locations after injury. Whichever is the case, some cells in the adult spinal cord appear to respond to tissue damage, acquiring some of the characteristics of embryonic neural progenitors. One week after injury, however, only a few $\mathrm{Pax}^{+}$and $\mathrm{Pax}^{+}$cells remained in injured tissue, and the number of $\mathrm{Nkx} 2.2^{+}$cells was also decreased. Thus, they emerged only transiently and may have differentiated, died, or stopped gene expression late after injury. This transient nature of their responses may be related to the limited regenerative potential of the adult spinal cord.

These observations, together with other recent studies, suggest that heterogeneous progenitor subtypes reside in the adult CNS (Temple and Alvarez-Buylla, 1999; Rao, 1999; Gage, 2000). However, a lack of definitive markers still hampers precise determi- nation of their identities and distribution in vivo. For instance, a recent study has proposed that $\mathrm{GFAP}^{+}$cells are neural stem cells in the forebrain (Doetsch et al., 1999). Furthermore, cells expressing markers for oligodendrocyte progenitors acquire the properties of stem cells in vitro (Palmer et al., 1999; Kondo and Raff, 2000). These observations suggest that cells expressing markers for glial cells may behave as stem cells or other neural progenitors under certain circumstances. In light of this idea, no specific markers are so far available that can distinguish distinct functional properties of different subtypes of neural progenitors. It also remains undetermined whether ependymal cells, or other cell types in the periventricular region, are stem cells (Morshead and van der Kooy, 2001). We found that ependymal cells in the adult spinal cord expressed Pax6 and nestin in response to injury. Thus, ependymal cells may display at least some aspects of the phenotypes of neural progenitors under certain circumstances. However, definitive determination of the growth and differentiation potential of ependymal cells and also of transcription factorexpressing cells that we detected in the parenchyma must await additional detailed studies. Molecular markers we reported here will be of use to further characterize heterogeneous progenitor subtypes in the adult spinal cord.

\section{Notch signaling and restricted neurogenesis in the adult spinal cord}

Despite the presence of neural progenitors, no production of new neurons has been detected in either the intact or injured spinal cord (Johansson et al., 1999; Namiki and Tator, 1999; Horner et al., 2000). Furthermore, neural progenitors could not differentiate into neurons when transplanted back into the spinal cord (Chow et al., 2000; Shihabuddin et al., 2000). Thus, de novo neurogenesis appears to be tightly restricted by the environment in vivo.

Here we suggest that Notch signaling may be involved in this restriction. We found that the expression of the Notch1 receptor was enhanced in vivo in response to injury. Furthermore, dominant-active Notch1 inhibited differentiation of adult progenitors in vitro. During development, Notch blocks neurogenesis by inhibiting the expression of various bHLH factors, including Ngn2 (Ma et al., 1996; de la Pompa et al., 1997). Likewise, activated Notch1 decreased the number of $\mathrm{Ngn} 2^{+}$cells in culture of adult progenitors, and moreover, no expression of Ngn2 could be detected in vivo in injured tissue. Conversely, the generation of neurons from adult progenitors could be enhanced by attenuation of Notch signals by the dominant-negative Notch ligand Dll1 and by forced expression of Ngn2.

A number of recent studies have demonstrated that Notch signaling regulates differentiation of neural progenitors at multiple steps during development (for review, see Wang and Barres, 2000). Our results are consistent with this idea, and we speculate that, like embryonic cells, adult progenitors undergo differentiation into neurons and glia through successive steps. Our data suggest that, during such sequential processes, Notch signaling inhibits an early differentiation step of progenitors, whereas it acts to promote astrogenesis at a later step. The early action of Notch probably involves the suppression of neurogenic bHLH factors, such as Ngn2, whereas it is currently unknown how Notch regulates differentiation of glia at a later step. Attenuation of Notch signals by Dll1-A may had enhanced neurogenesis at the expense of astrogenesis. Alternatively, Dll1-A may have supported the selective survival of neurons, thereby simply decreasing the relative ratio of astrocytes. Furthermore, forced expression of Ngn2 did not affect the differentiation of astrocytes, although it showed 
a much stronger effect on the generation of neurons than that of Dl11-A. It is also not known why neither Dll1-A nor Ngn2 affected the generation of oligodendrocytes. Thus, the actions of Notch signaling and neurogenic bHLH factors in adult progenitors appears to be more complex than previously thought and must await additional intensive studies.

In any case, the above results collectively suggest that Notch signaling is one of the mechanisms that restrict production of neurons from adult progenitors. In the adult spinal cord, neural progenitors are thought to be surrounded by many mature cells. Although lack of appropriate antibodies currently precludes identification of ligand-expressing cells, mature neurons and glia may express Notch ligands and inhibit differentiation of neurons from endogenous progenitors. Notch signaling may also be involved in regulating astrogenesis from adult progenitors in vivo. If adult progenitors could bypass Notch-dependent inhibition of an early differentiation step under certain conditions, Notch signals may selectively stimulate astrogenesis in injured tissue. Such a possibility has been suggested in recent studies (Frisen et al., 1995; Johansson et al., 1999; Namiki and Tator, 1999; Horner et al., 2000).

In conclusion, our findings provide an important clue toward realizing the possibility of repairing the damaged spinal cord by activating the latent regenerative potential of endogenous neural progenitors (Svendsen and Smith, 1999; Horner and Gage, 2000). Our results suggest that both the intrinsic properties of adult progenitors and the in vivo environment in the adult spinal cord limit significant regeneration of damaged tissues. We suggest that some strategies to modulate Notch signaling will be important to generate new neurons from endogenous progenitors in vivo. Attenuation of Notch signaling and/or forced expression of neurogenic bHLH factors may enable selective enhancement of neurogenesis in injured tissue. Such strategies may also block excess glial scar formation by inhibiting differentiation of astrocytes. Furthermore, we will need to overcome the inability of adult progenitors to generate specific neuronal subtypes. Thus, combinatorial applications of many different strategies may be necessary to facilitate significant structural and functional repair of the damaged adult spinal cord.

\section{REFERENCES}

Beattie MS, Bresnahan JC, Komon J, Tovar CA, Van Meter M, Anderson DK, Faden AI, Hsu CY, Noble LJ, Salzman S, Young W (1997) Endogenous repair after spinal cord contusion injuries in the rat. Exp Neurol 148:453-463.

Chambers CB, Peng Y, Nguyen H, Gaiano N, Fishell G, Nye JS (2001) Spatiotemporal selectivity of response to Notch1 signals in mammalian forebrain precursors. Development 128:689-702.

Chow SY, Moul J, Tobias CA, Himes BT, Liu Y, Obrocka M, Hodge L, Tessler A, Fischer I (2000) Characterization and intraspinal grafting of EGF/bFGF-dependent neurospheres derived from embryonic rat spinal cord. Brain Res 874:87-106.

Dawson MRL, Levine JM, Reynolds R (2000) NG2-expressing cells in the central nervous system: are they oligodendroglial progenitors? J Neurosci Res 61:471-479.

de la Pompa JL, Wakeham A, Correia KM, Samper E, Brown S, Aguilera RJ, Nakano T, Honjo T, Mak TW, Rossant J, Conlon RA (1997) Conservation of the Notch signalling pathway in mammalian neurogenesis. Development 124:1139-1148.

Doetsch F, Caille I, Lim DA, Garcia-Verdugo JM, Alvarez-Buylla A (1999) Subventricular zone astrocytes are neural stem cells in the adult mammalian brain. Cell 97:703-716.

Dutton R, Yamada T, Turnley A, Bartlett PF, Murphy M (1998) Sonic hedgehog promotes neuronal differentiation of murine spinal cord precursors and collaborates with neurotrophin 3 to induce Islet-1. J Neurosci 19:2601-2608.

Frisen J, Johansson CB, Torok C, Risling M, Lendahl U (1995) Rapid, widespread, and long lasting induction of nestin contributes to the generation of glial scar tissue after CNS injury. J Cell Biol 132:453-464.
Gage FH (2000) Mammalian neural stem cells. Science 287:1433-1438.

Gritti A, Parati EA, Cova L, Frolichsthal P, Galli R, Wanke E, Faravelli L, Morassutti DJ, Roisen F, Nickel DD, Vescovi AL (1996) Multipotential stem cells from the adult mouse brain proliferate and self-renew in response to basic fibroblast growth factor. J Neurosci 16:1091-1100.

Horner PJ, Gage FH (2000) Regenerating the damaged central nervous system. Nature 407:963-970.

Horner PJ, Power AE, Kempermann G, Kuhn HG, Palmer TD, Winkler J, Thal LJ, Gage FH (2000) Proliferation and differentiation of progenitor cells throughout the intact adult rat spinal cord. J Neurosci 20:2218-2228.

Johansson CB, Momma S, Clarke DL, Risling M, Lendahl U, Frisen J (1999) Identification of a neural stem cell in the adult mammalian central nervous system. Cell 96:25-34.

Kalyani A, Hobson K, Rao MS (1997) Neuroepithelial stem cells from the embryonic spinal cord: isolation, characterization, and clonal analysis. Dev Biol 186:202-223.

Kalyani A, Piper D, Mujtaba T, Lucero MT, Rao MS (1998) Spinal cord neuronal precursors generate multiple neuronal phenotypes in culture. J Neurosci 18:7856-7868.

Kamei Y, Inagaki N, Nishizawa M, Tsutsumi O, Taketani Y, Inagaki M (1998) Visualization of mitotic radial glial lineage cells in the developing rat brain by $\mathrm{Cdc} 2$ kinase-phosphorylated vimentin. Glia 23:191-199.

Kehl LJ, Fairbanks CA, Laughlin TM, Wilcox GL (1997) Neurogenesis in postnatal rat spinal cord: a study in primary culture. Science 276:586-589.

Kondo T, Raff M (2000) Oligodendrocyte precursor cells reprogrammed to become multipotential CNS stem cells. Science 289:1754-1757.

Lee JE, Hollenberg SM, Snider L, Turner DL, Lipnick N, Weintraub H (1995) Conversion of Xenopus ectoderm into neurons by NeuroD, a basic helix-loop-helix protein. Science 268:836-844.

Lendahl U, Zimmerman LB, McKay RDG (1990) CNS stem cells express a new class of intermediate filament protein. Cell 60:585-595.

Lu QR, Yuk D, Alberta JA, Zhu Z, Pawlitzky I, Chan J, McMahon AP, Stiles CD, Rowitch DH (2000) Sonic hedgehog-regulated oligodendrocyte lineage genes encoding bHLH proteins in the mammalian central nervous system. Neuron 25:317-329.

Ma Q, Kintner C, Anderson DJ (1996) Identification of neurogenin, a vertebrate neuronal determination gene. Cell 87:43-52.

Marmur R, Mabie PC, Gokhan S, Song Q, Kessler JA, Mehler MF (1998) Isolation and developmental characterization of cerebral cortical multipotent progenitors. Dev Biol 204:577-591.

McKay R (1997) Stem cells in the central nervous system. Science 276:66-71.

McTigue DM, Wei P, Stokes BT (2001) Proliferation of NG2-positive cells and altered oligodendrocyte numbers in the contused rat spinal cord. J Neurosci 21:3392-3400.

Miura T, Tanaka S, Seichi A, Arai M, Goto T, Katagiri H, Asano T, Oda H, Nakamura K (2000) Partial functional recovery of paraplegic rat by adenovirus-mediated gene delivery of constitutively active MEK1. Exp Neurol 166:115-126.

Morita S, Kojima T, Kitamura T (2000) Plat-E: an efficient and stable system for transient packaging of retroviruses. Gene Ther 7:1063-1066.

Morshead CM, van der Kooy D (2001) A new "spin" on neural stem cells? Curr Opin Neurobiol 11:59-65.

Nakafuku M, Nakamura S (1995) Establishment and characterization of a multipotential neural cell line that can conditionally generate neurons, astrocytes, and oligodendrocytes in vitro. J Neurosci Res $41: 153-168$

Nakagawa Y, Kaneko T, Ogura T, Suzuki T, Torii M, Kaibuchi K, Arai K, Nakamura S, Nakafuku M (1996) Role of cell-autonomous mechanisms for differential expression of region-specific transcription factors in neuroepithelial cells. Development 122:2449-2464.

Namiki J, Tator CH (1999) Cell proliferation and nestin expression in the ependyma of the adult rat spinal cord after injury. J Neuropathol Exp Neurol 58:489-498.

Nieto M, Schuurmans C, Brz O, Guillemot F (2001) Neural bHLH genes control the neuronal versus glial fate decision in cortical progenitors. Neuron 29:401-413.

Nye JS, Kopan R, Axel R (1994) An activated Notch suppresses neurogenesis and myogenesis but not gliogenesis in mammalian cells. Development 120:2421-2430.

Palmer TD, Ray J, Gage FH (1995) FGF-2-responsive neuronal progenitors reside in proliferative and quiescent regions of the adult rodent brain. Mol Cell Neurosci 6:474-486.

Palmer TD, Markakis EA, Willhoite AR, Safar F, Gage FH (1999) Fibroblast growth factor-2 activates a latent neurogenic program in neural stem cells from diverse regions of the adult CNS. J Neurosci 19:8487-8497.

Rao MS (1999) Multipotent and restricted precursors in the central nervous system. Anat Rec 257:137-148.

Redmond L, Oh SR, Hicks C, Weinmaster G, Ghosh A (2000) Nuclear Notch1 signaling and the regulation of dendritic development. Nat Neurosci 3:30-40. 
Richards LJ, Murphy M, Dutton R, Kilpatrick TJ, Puche AC, Key B, Tan SS, Talman PS, Bartlett PF (1995) Lineage specification of neuronal precursors in the mouse spinal cord. Proc Natl Acad Sci USA 92:10079-10083.

Sestan N, Artavanis-Tsakonas S, Rakic P (1999) Contact-dependent inhibition of cortical neurite growth mediated by notch signaling. Science 286:741-746.

Shawber C, Nofziger D, Hsieh JJ, Lindsell C, Bogler O, Hayward D, Weinmaster G (1996) Notch signaling inhibits muscle cell differentiation through a CBF1-independent pathway. Development 122:3765-3773.

Shihabuddin LS, Ray J, Gage FH (1997) FGF-2 is sufficient to isolate progenitors found in the adult mammalian spinal cord. Exp Neurol 148:577-586.

Shihabuddin LS, Horner PJ, Ray J, Gage FH (2000) Adult spinal cord stem cells generate neurons after transplantation in the adult dentate gyrus. J Neurosci 20:8727-8735.

Sun Y, Nadal-Vicens M, Misono S, Lin MZ, Zubiaga A, Hua X, Fan G, Greenberg ME (2001) Neurogenin promotes neurogenesis and inhibits glial differentiation by independent mechanisms. Cell 104:365-376.

Svendsen CN, Smith AG (1999) New prospects for human stem-cell therapy in the nervous system. Trends Neurosci 22:357-364.

Takebayashi H, Yoshida S, Sugimori M, Kosako H, Kominami R, Nakafuku M, Nabeshima Y (2000) Dynamic expression of basic helix-loophelix Olig family members: implication of Olig2 in neuron and oligodendrocyte differentiation and identification of a new member, Olig3. Mech Dev 99:143-148.

Tanabe Y, Jessell TM (1996) Diversity and pattern in the developing spinal cord. Science 274:1115-1123.

Tanigaki K, Nogaki F, Takahashi J, Tashiro K, Kurooka H, Honjo T (2001) Notch1 and Notch3 instructively restrict bFGF-responsive multipotent neural progenitor cells to an astroglial fate. Neuron 29:45-55.
Temple S, Alvarez-Buylla A (1999) Stem cells in the adult mammalian central nervous system. Curr Opin Neurobiol 9:135-141.

Torii M, Matsuzaki F, Osumi N, Kaibuchi K, Nakamura S, Casarosa S, Guillemot F, Nakafuku M (1999) Transcription factors Mash-1 and Prox-1 delineate early steps in differentiation of neural stem cells in the developing central nervous system. Development 126:443-456.

Wang S, Barres BA (2000) Up a notch: instructing gliogenesis. Neuron 27:197-200.

Wang S, Sdrulla AD, diSibio G, Bush G, Nofziger D, Hicks C, Weinmaster G, Barres BA (1998) Notch receptor activation inhibits oligodendrocyte differentiation. Neuron 21:63-75.

Weinmaster G (1997) The ins and outs of notch signaling. Mol Cell Neurosci 9:91-102.

Weiss S, Dunne C, Hewson J, Wohl C, Wheatley M, Peterson AC, Reynolds BA (1996) Multipotent CNS stem cells are present in the adult mammalian spinal cord and ventricular neuroaxis. J Neurosci 16:7599-7609.

Xu X, Cai J, Fu H, Wu R, Qi Y, Modderman G, Liu R, Qiu M (2000) Selective expression of Nkx-2.2 transcription factor in chicken oligodendrocyte progenitors and implications for the embryonic origin of oligodendrocytes. Mol Cell Neurosci 16:740-753.

Zappone MV, Galli R, Catena R, Meani N, Biasi SD, Mattei E, Tiveron C, Vescovi AL, Lovell-Badge R, Ottolenghi S, Nicolis SK (2000) Sox2 regulatory sequences direct expression of a $\beta$-geo transgene to telencephalic neural stem cells and precursors of the mouse embryo, revealing regionalization of gene expression in CNS stem cells. Development 127:2367-2382

Zhou Q, Wang S, Anderson DJ (2000) Identification of a novel family of oligodendrocyte lineage-specific basic helix-loop-helix transcription factors. Neuron 25:331-343. 